\title{
Relevansi Prestasi Belajar Sebagai Prediktor Penalaran Moralitas (Studi Kasus di SMA Negeri 5 Samarinda)
}

\author{
Siti Murti ${ }^{*}$, Heryanto** \\ ${ }^{*}$ Sekolah Menengah Atas Negeri 5 Samarinda \\ **Studi Pembangunan, Universitas Mulawarman \\ email: sitimurti88@yahoo.co.id
}

\section{INFO ARTIKEL}

Riwayat Artikel:

Diterima: 8 Juni 2019

Disetujui: 10 Desember 2019

\section{Kata kunci:}

Achievement learning

Student

Prestasi belajar

Siswa

Moralitas

\section{Alamat Korespondensi:}

Siti Murti

SMA Negeri 5 Samarinda

Jln. Ir. H. Juanda Nomor 01 Samarinda

email: sitimurti88@yahoo.co.id

\begin{abstract}
ABSTRAK
Abstract: The purpose of this study is to analyze the relevance of morality with student achievement so that its contribution to learning achievement is known. This research includes the type of verification research conducted through data collection in the field using survey methods. The unit of analysis was taken using a simple random sampling technique. Data was collected through observation, interviews, questionnaires, and documentation. This study consisted of two variables, namely morality as the independent variable, and student learning achievement as the dependent variable. The results of the study show that the correlation between moral reasoning and student achievement is 0.683 (the degree of relationship is strong). This means that students' morality reasoning is $46.65 \%$ determined by learning achievement factors, and $53.35 \%$ is determined by other factors.
\end{abstract}

\begin{abstract}
Abstrak: Tujuan penulisan artikel ini ialah menganalisis relevansi prestasi belajar dengan moralitas siswa, sehingga dapat diketahui kontribusinya terhadap penalaran moralitas dalam perilaku sosial. Penelitian ini termasuk jenis penelitian verifikatif yang dilakukan melalui pengumpulan data di lapangan dengan menggunakan metode survey. Unit analisis diambil menggunakan teknik sampel acak sederhana. Data dikumpulkan melalui observasi, wawancara, kuesioner dan dokumentasi. Peneltian ini terdiri atas dua variabel yaitu prestasi belajar siswa sebagai independent variable, dan penalaran moralitas sebagai dependent variabel. Hasil penelitian menunjukkan bahwa penalaran moralitas memiliki korelasi dengan prestasi belajar siswa, yaitu sebesar 0,683 (derajat hubungan kuat). Hal ini berarti penalaran moralitas siswa sebesar 46,65\% ditentukan oleh faktor prestasi belajarnya, dan 53,35.\% ditentukan faktor lain.
\end{abstract}

\section{LATAR BELAKANG}

Pembelajaran berbasis karakter telah dilaksanan oleh seluruh lembaga pendidikan persekolahan di Indonesia, mulai sekolah dasar sampai dengan sekolah menengah atas. Seluruh penyampaian kompetensi mata pelajaran harus mengacu pada terbentuknya perilaku moral yang berlaku di masyarakat. Pertanyaan yang muncul adalah apakah hasil pembelajaran berbasis karakter memiliki relevansi dengan moralitas siswa? Atau dengan kata lain prestasi belajar dapat menjadi prediktor terhadap perilaku siswa, sehingga perilaku menyimpang dapat dideteksi lebih dini. Perilaku menyimpang di kalangan remaja memiliki kecenderungan yang terus meningkat, baik dari aspek kuantitas maupun kualitas.

Perilaku menyimpang memberikan dampak terhadap diri remaja, orang tua dan anggota masyarakat (Wuryati, 2012). Dampak yang nampak kepermukaan, selain menimbulkan kerugian material tetapi juga imaterial seperti gangguan moralitas. Penalaran moralitas remaja menjadi aspek penting bagi kepentingan individu yang besangkutan, dan masa depan bangsa, sebagaimana diungkapkan (Romeral, Fernández, \& Fraguela, 2018) moral reasoning is thus one of the most important and decisive ingredients of moral behavior. Penalaran moralitas pada diri seseorang akan menghasilkan kemampuan berpikir kritis, sehingga menghasilkan perilaku moral pada diri yang bersangkutan. In the context of democratic citizenship, critical thinking could be claimed to have a direct link with moral judgment competences in modern societies (Samanc1, 2015). Dengan demikian, kesalahan penalaran dalam berpikir moral akan menghasilkan perilaku yang menyimpang dari nilai-nilai moral yang berlaku di masyarakat. Penalaran atau rasioning merupakan proses berpikir yang berpijak pada kemampuan pengamatan indera, sehingga menghasilkan konsep, pengertian, atau simpulan. 
Morality comes from the Latin word, moralis, which means, "customs, manners, or patterns of behaviour that conform to the standards of the group". At every age, the individual is judged by how closely he conforms to the groups' standards, and he is labelled "moral" or "immoral", accordingly (Volokh, 2007). Di kalangan pelajar masih terdapat perilaku menyimpang di lingkungan masyarakat, padahal seyogyanya pelajar memiliki moralitas berpikir yang baik. Pembelajaran berbasis karakter seharusnya menghasilkan siswa yang berprestasi dan juga bermoral. Menurut Edwards (1967) sebagaimana dikutif Siyaswati (2016) that a morality contains (1) beliefs about the nature of the man, (2) belief about ideals, about what is good or desirable or worthy or pursuit for its own sake, (3)rules laying down what ought to be done and (4) motives that incline us to choose the right or the wrong course. We learn as children that we should be unselfish, that we should not tell lies. Jadi moralitas pada hakekatnya berkaitan dengan keyakinan tentang hakekat atau sifat manusia, cita-cita baik yang diinginkan, aturan yang harus dilakukan, dan dorongan (motif) untuk memilih yang benar atau salah. Oleh karena itu, anak atau siswa sepantasnya tidak mementingkan dirinya sendiri atau melakukan yang tidak terpuji seperti berbohong atau lainnya. There have been several social problems in the recent decade, for example; crimes, drug abuse, sexual harassment. They are all from moral and ethical decline. Although several campaigns raising awareness of morality and ethics concern have been activated by both public and private organizations, the problems still continue (Sanwong, 2010).

Menurut Herningsih, Fatmawati, \& Salim (2015) kewajiban siswa pada usia sekolah seharusnya menuntut ilmu ternyata sebagian dari mereka melakukan tindakan-tindakan yang salah dan kurang terpuji. Kesalahan yang diperbuat para siswa hanya akan menyenangkan teman sebayanya dan sering menimbulkan kekhawatiran serta perasaan yang tidak menyenangkan bagi lingkungannya, orangtuanya. Kesalahan-kesalahan yang menimbulkan kekesalan lingkungan inilah yang sering disebut sebagai perilaku menyimpang. Jika dibandingkan dengan persoalan sosial negara lain, Indonesia masih relatif tidak serumit negara Hongkong. Mak (2014) revealed, Hongkong is encountering a complicated moral culture. We can see critics of the government, the culture of the legislation council, and of the university orientation camp scandal. These all spark the controversy about moral conflicts among mass media and society. Complaints and impolite behaviour are often seen.

Penelitian-penelitian yang dilakukan para akhli yang membahas moral biasanya menyangut tiga hal, seperti Ruyters dan Miedema, in his research on moral education, three topics have been particularly prevalent, namely virtue ethics, civic education and sex education (Ruyters \& Miedema, 2011). Tiga hal ini harus selalu menjadi perhatian lembaga pendidikan, baik lembaga persekolahan maupun lembaga pendidikan lainnya. Ideally, a school allows the child to guide his or her own development (Ruyters \& Miedema, 2011). Di sisi lain, sebenarnya siswa atau pelajar berusaha keras untuk menghindar dari perbuatan tak terpuji atau yang disebut perilaku menyimpang.

Begitu juga penelitian yang dilakukan Sniras \& Malinauskas (2005) states that school prove that schoolchildren aged from 13 to 15 try very hard to be sensitive towards others and are trying much harder to console to a statistically significant extent, in comparison to the 10 to 12 age group. Oleh karena itu, untuk mengantarkan kesuksesan siswa perlu ada upaya pembangunan karena pada siswanya. The road to success with character building is paved with (1) content that conveys universal moral principles and virtues, and (2) instructional methods that ensure their internalization and the cultivation of moral emotions, moral commitments, and moral reasoning that necessarily underlie moral action (Vessels \& Huitt, 2011).

Selanjutnya terdapat penelitian yang melibatkan berbagai aspek termasuk ketepatan waktu, kejujuran, persatuan, tanggung jawab, dan keberlanjutan untuk mengungkap moralitas siswa. Sebagaimana diungkapkan Sanwong (2010) states the research involves mixed methodology, aiming to develop undergraduate students' morals and ethics in five dimensions including punctuality, honesty, unity, responsibility, and sustainability. Kelima dimensi tersebut dianalisis sesuai instrument penelitian yang dilakukannya. The instruments contained a survey on morals and ethics, an attitude appraisal, and an observation form. The overall Cronbach's alpha coefficient was .875. The outcomes disclosed the efficiency of the teaching model using, moral-based thinking process skill on the progress of student morality and ethics ( $p<.05)$. The increase in these dimensions can be predicted by the subjects' attitudes. All five dimensions could be categorized into two subcomponents. Suitable values comprised comprehension, being aware, and clarification potential. Unsuitable values blended among ignorance, morality employed (Sanwong, 2010).

Pembangunan karakater yang mengharapkan perilaku moral yang baik diperlukan tahapan yang sesuai, karena manusia memiliki tahap perkembangan menuju kedewasaan moral. Tahap perkembangan menurut Kohlberg (1969) yang dikutif Samanci (2015) explains moral development in stages: (1) pre-conventional stage (obedience and punishment driven, self-interest driven), (2) conventional stage (interpersonal accord and conformity driven, authority and social order driven), and (3) post-conventional stage (social contract driven, universal ethical principles driven). Perilaku moral sangat erat kaitannya dengan ucapan yang layak diucapkan dan tidak layak diucapkan, dan aktivitas yang layak dilakukan atau tidak dilakukan. Sarana yang dipandang relevan dan efektif dalam pembangunan karakter untuk terwujudnya moral baik adalah pendidik. Sudrajat (2011) menyatakan bahwa pendidikan pada hakikatnya memiliki dua tujuan, yaitu membantu manusia untuk menjadi cerdas dan pintar (smart), dan membantu mereka menjadi manusia yang baik (good). Menjadikan manusia cerdas dan pintar, boleh jadi mudah melakukannya, tetapi menjadikan manusia agar menjadi orang yang baik dan bijak, tampaknya jauh lebih sulit atau bahkan sangat sulit.

Atas fakta ini, Pemerintah Indonesia menyadari hal itu, maka melalui kementerian terkait membangun sistem penyelenggaraan pembelajaran yang berbasis karakter. Pembelajaran menurut Fathoni (2015) merupakan bantuan yang diberikan pendidik agar dapat terjadi proses pemerolehan ilmu dan pengetahuan, penguasaan kemahiran dan tabiat, serta pembentukan sikap dan kepercayaan pada peserta didik. Dengan kata lain, pembelajaran adalah proses untuk membantu peserta didik agar dapat belajar dengan baik. Proses pembelajaran dialami sepanjang hayat oleh seorang manusia serta dapat 
berlaku di manapun dan kapanpun. Terkait dengan moralitas, Volokh (2007) revealed that the moral sensibility of a person is initiated during infancy, constructed and consolidated through experiences during childhood and adolescence. This will reflect in the personality of the adult. Menurut Erikson (1968) yang dikutif oleh Qashmer, (2016), under optimal conditions, a clear sense of identity develops during adolescence and emerging adulthood. Pendidikan karakter merupakan karakteristik lingkungan sehat dan baik yang mendorong aspek perilaku moralitas di masyarakat.

Pendidikan karakter dapat dilakukan pada berbagai tingkatannya, seperti diungkapkan oleh akhli pendidikan, Qashmer (2016) states that character education can be delivered at different levels. For example, it can be delivered at the school level, a classroom level, or as an extra-curricular club. Pendidikan sebagai wahana pembinaan karakter adalah sangat tepat, pendidikan dapat membantu siswa dalam menyadari dan mengidentifikasi nilai-nilai mereka sendiri serta nilainilai orang lain. Pendidikan membantu siswa, supaya mampu berkomunikasi secara terbuka dan jujur dengan orang lain, supaya mereka mampu menggunakan secara bersama-sama kemampuan berpikir rasional dan kesadaran emosional, untuk memahami perasaan, nilai-nilai, dan pola tingkah laku mereka sendiri (Hadi, 2014).

Pada awalnya pendidikan karakter lebih banyak ditekankan pada mata pelajaran agama yang diharapkan membangun karakter atau moral bertanggung jawab. Moral development is related to the rules that people have for their interaction with others. It is concerned with the acceptance of morality which brings along certain forms of behaviour, attitudes and values in an individual. In the early stages, the child simply tries to avoid punishment as he cannot distinguish "right" from "wrong”. Over time children's values are influenced by parents and educators as role models. Children's moral development is linked to their intellectual development (Volokh, 2007). Berdasar pada kutifan di atas nampak jelas ada harapan bahwa perkembangan moral seseorang berkaitan dengan perkembangan intelektualnya.

Penelitian yang dilakukan Pertiwi (2017) menyatakan ada pengaruh yang signifikan antara prestasi belajar terhadap moralitas siswa. Hal ini berarti bahwa prestasi belajar dapat menjadi prediktor perilaku moral siswa. Selanjutnya Pertiwi mengkaji bahwa pengetahuan moral (moral knowing) dengan perilaku moral (moral action) memiliki hubungan pengaruh yang positif (Pertiwi, 2017). Pembelajaran yang berbasis karakter (moral) diharapkan terdapat keterkaitan antara prestasi belajar dengan perilaku moral siswa. Kajian ini berfokus pada dua variabel yaitu prestasi belajar dan moralitas siswa. Prestasi belajar yang terkait dengan moralitas dalam konteks tindakan interaksi sosial adalah mata pelajaran sosiologi. Tindakan dalam interaksi antar kelompok, asal-usul pertumbuhan kelompok, dan pengaruh kegiatan kelompok terhadap anggotanya juga tidak lepas dari kajian sosiologi (Buddyarti, 2003). Sociology provides an understanding of social issues and patterns of behavior. It helps us identify the social rules that govern our lives (Stolley, 2005). Penalaran moralitas seseorang akan begitu nampak melalui interaksi sosial, baik individual maupun kelompok. Pertanyaan mendasar kajian ini adalah apakah prestasi belajar sosiologi memiliki relevansi dengan penalaran moralitas? Melalui kajian ini diharapkan dapat mengungkap kontribusi mata pelajaran sosiologi terhadap pembentukan penalaran moral dan proses pembelajaran yang tepat untuk meningkatkan prestasi belajar sekaligus moral siswa.

\section{METODE}

Pendekatan penelitian yang digunakan ialah metode deskriptif atau sering disebut juga taxonomic research yaitu untuk mengeksplorasi dan mengklarifikasi suatu fenomena sosial dengan mendeskripsikan sejumlah variabel yang berkenaan dengan masalah unit yang diteliti (Murti \& Heryanto, 2016). Tujuan penelitian ini ialah ingin memberikan penjelasan sesuai fakta tentang relevansi prestasi belajar dengan penalaran moral siswa di Sekolah Menengah Atas Negeri 5 Samarinda. Populasi dalam penelitian ini ialah seluruh siswa Sekolah Menengah Atas Negeri 5 Samarinda. Sampel diambil secara probabilistik dengan simple random sampling, yaitu suatu teknik pengambilan sampel dilakukan secara acak sederhana. Ukuran populasi 1.024 maka dengan menggunakan rumus tabel Isaac dan Michael pada derajat kesalahan 5\%, diperoleh ukuran sampel 265, namun koesiner yang kembali memenuhi syarat hanya 258 siswa. Ukuran sampel ini masih dianggap layak, karena ada beberapa akhli yang mengambil 10\% dari populasi sosial.

Variabel yang menjadi perhatian penelitian, yaitu prestasi belajar siswa sebagai independent variable dan penalaran moralitas sebagai dependent variable. Indikator prestasi belajar diukur berdasarkan nilai mata pelajaran sosiologi pada raport siswa. Pertimbangan nilai mata pelajaran sosiologi karena Sosiologi merupakan multidisiplin yang membahas norma, adat istiadat, dan perilaku sosial di masyarakat. Variabel moralitas berdasarkan pada 11 indikator karakter yang masing indikator terdapat 5 sampai 6 sub-indikator. Kesebelas indikator tersebut antara lain: religius, jujur, cerdas, adil, tanggung jawab, peduli, toleran, demokratis, cinta tanah air, tangguh, dan santun (Sutrisno, 2015). Selanjutnya masing-masing indikaor diukur menggunakan skala Likert pada rentang 1 sampai 5. Pengubahan data ordinal ke interval menggunakan pendekatan software succesive interval. Pengubahan data ordinal ke interval diperlukan untuk menganalisis lebih lanjut yang mempersyaratkan data interval.

Waktu yang digunakan dalam penelitian ini selama dua bulan Februarti sampai dengan Maret 2019. Isi kegiatan penelitian meliputi pra-survai, mengurus perijinan penelitian orientasi pendahuluan, mengumpulkan data, menguji validitas dan reliabilitas data, analisis data dan menyusun laporan. Alat yang digunakan data iala kuesioner (daftar pertanyaan) yang diajukan kepada siswa. Uji validitas menggunakan pendekatan analisis faktor karena setiap item dengan item lainnya memiliki faktor yang berbeda. Pendekatan uji validitas dan reliabilitas instrumen diperlukan karena instrumen penelitian ini menggunakan angket dengan data ordinal bertingkat, yaitu skala likert. Uji validitas berdasarkan content untuk menghasilkan nilai koefisien item instrument terhadap totalnya dengan Pearson Product moment. Dalam menentukan layak 
atau tidaknya suatu item yang digunakan, biasanya digunakan uji signifikansi valid jika berkorelasi signifikan terhadap skor total (Dewi, 2018). Uji reliabilitas instrument untuk melihat koefisien Cronbach's Alpha. Keseluruhan analisis dalam penelitian ini menggunakan fasilitas program statistik SPSS (Statistical Package for the Social Sciences)

HASIL

\section{Deskripsi Data Hasil Angket Prestasi Belajar}

Berdasarkan hasil penelitian terhadap independent variable diketahui bahwa secara umum prestasi belajar siswa di SMA Negeri 5 berada pada kategori baik, karena sebanyak 98,84\%, prestasi belajar siswa 70 atau lebih, sedangkan nilai rata-rata 80,93 berada di atas nilai kriteria ketuntasan minimal (KKM) untuk mata pelajaran sosiologi adalah 70 . Nilai prestasi belajar tertinggi 92 dan terrendah 70 dengan standar deviasi 3,872. Tabel 1. berikut menyajikan prestasi belajar.

Tabel 1. Prestasi Belajar Siswa

\begin{tabular}{lcrr}
\hline \multicolumn{1}{c}{ Kategori } & $\begin{array}{c}\text { Nilai } \\
\text { Sosiologi }\end{array}$ & f & \% \\
\hline Kurang & $<70,00$ & 3 & 1,16 \\
Cukup & $70,00-74,99$ & 19 & 7,37 \\
Baik & $75,00-79,99$ & 233 & 90,31 \\
Sangat Baik & $>79,99$ & 3 & 1,16 \\
\hline \multicolumn{4}{c}{ Sumber: Diolah dari Nilai Raport, 2019 }
\end{tabular}

Kondisi prestasi belajar siswa berada pada standar minimal yaitu 70 atau lebih di atasnya. Mengacu pada tabel 1 maka dapat disimpulkan hampir seluruh siswa telah memenuhi (KKM, kriteria ketuntasan minimal ) atau standar minimal ketuntasan pada mata pelajaran sosiologi. Hal ini cukup beralasan karena siswa yang mendapat nilai kurang dari 70 sering membolos atau tidak masuk kelas tanpa alasan yang jelas.

\section{Deskripsi Data Hasil Angket Aspek-Aspek Moralitas}

Penalaran moralitas siswa menyangkut 11 aspek yang diukur berdasarkan sikap siswa terhadap kesebelas aspek tersebut. Aspek yang pertama adalah religius yang sering dikaitkan dengan agama. Dalam upaya meningkatkan kesadaran beragama, SMA Negeri 5 merancang sedemikian rupa untuk tumbuhnya budaya religius di lingkungan sekolah. Penyediaan fasilitas ibadah dan berperilaku sesuai ajaran agama yang dianutnya merupakan program budaya religius. Menurut Fathurrohman (2016:27), budaya religius adalah upaya terwujudnya nilai-nilai ajaran agama sebagai tradisi dalam berperilaku dan budaya organisasi yang diikuti oleh seluruh warga di lembaga pendidikan tersebut. Melalui budaya religius ini yang bersumber dari tujuan pendidikan karakter diharapkan mencapai hasil belajar yang tinggi dan berbudi luhur.

Tabel 2. Gambaran Sikap Religius Siswa

\begin{tabular}{lcrr}
\hline \multicolumn{1}{c}{ Uraian } & $\begin{array}{c}\text { Skor Sikap } \\
\text { Religius }\end{array}$ & f & $\%$ \\
\hline Sangat Tidak Baik & $\leq 5.00$ & 2 & 0,78 \\
Tidak Baik & $5.01-10.00$ & 10 & 3,88 \\
Cukup Baik & $10.01-15.00$ & 113 & 43,80 \\
Baik & $15.01-20.00$ & 81 & 31,40 \\
Sangat Baik & $\geq 20.01$ & 52 & 20,16 \\
\hline & & 258 & 100,00 \\
\hline
\end{tabular}

Sumber: Diolah dari angket nomor: 1, 2, 3, 4, dan 5 .

Gambaran sikap keagamaan siswa menunjukkan kondisi yang baik, yaitu lebih dari setengahnya (51,56\%), dan hanya sebagaian kecil saja memperlihatkan sikap yang tidak baik. Kondisi seperti ini sungguh menggembirakan dilihat dari aspek religius siswa yang menaruh perhatian terhadap agama yang dianutnya. Agama Islam dianut oleh kebanyak siswa, hampir seluruhnya beragama Islam. Sikap religius tidak hanya pada batas permukaan, tetapi juga daya penalarannya. Through developing awareness and appreciation of the value of each individual in a diverse society, religious and moral education engenders responsible attitudes to other people. This awareness and appreciation will assist in counteracting prejudice and intolerance as children and young people consider issues such as sectarianism and discrimination more broadly (Scottish Government, 2009:2). Berdasar pada aspek religius maka akan tumbuh perilaku jujur pada diri siswa dalam kehidupan seharai-hari. Perilaku jujur mencermin keimanan, etika dan moral seseorang, dia mengakui sang pencipta dan yakin akan pembalasan surga atas perbuatan baik dan neraka terhadap perilaku munkar (Muhasin, 2017:176). Gambaran Sikap kejujuran siswa disajikan pada tabel 3 berikut. 
Tabel 3. Gambaran Sikap Kejujuran Siswa

\begin{tabular}{lcrr}
\hline \multicolumn{1}{c}{ Kategori } & $\begin{array}{c}\text { Skor Sikap } \\
\text { Kejujuran }\end{array}$ & f & \% \\
\hline Sangat Tidak Baik & $\leq 5.00$ & 1 & 0,39 \\
Tidak Baik & $5.01-10.00$ & 19 & 7,36 \\
Cukup Baik & $10.01-15.00$ & 106 & 41,09 \\
Baik & $15.01-20.00$ & 83 & 32,17 \\
\hline Sangat Baik & $\geq 20.01$ & 49 & 18,99 \\
\hline & & 258 & 100,00
\end{tabular}

Sumber: Diolah dari angket nomor: 6, 7, 8, 9, dan 10.

Sikap religius memberi implikasi terhadap berbagai perilaku, termasuk perilaku jujur. Kejujuran siswa pada umumnya bersikap jujur (91,65\%), dan hanya sebagian kecil yang menilai tidak baik terhadap sikap jujur (8,35\%). Sikap demikian, tentunya sebagai konsekuensi dari sikap religius siswa yang baik. Selain karakter religius dan jujur, siswa perlu memiliki sikap kecerdasan yang layak, karena tujuan pendidikan adalah mencerdaskan. Kecerdasan dalam kajian ini merupakan implementasi dari kemampuan kognitif untuk belajar menyelesaikan persoalan untuk mencapai prestasi. Prestasi sering diidentikan dengan kecerdasan karena setiap kecerdasan memiliki prestasi. Sesuai dengan perkembangan ilmu pengetahuan psikologi, telah disusun delapan macam kecerdasan, yaitu linguistik, matematis-logis, ruang-spasial, kinestetik-badani, musikal, interpersonal, intrapersonal, dan naturalis (Aziz, 2011:iv). Tabel 4 berikut menyajikan sikap kecerdasan siswa SMA Negeri 5 Samarinda.

Tabel 4. Gambaran Sikap Kecerdasan Siswa

\begin{tabular}{lcrr}
\hline \multicolumn{1}{c}{ Kategori } & $\begin{array}{c}\text { Skor Sikap } \\
\text { Kecerdasan }\end{array}$ & f & \% \\
\hline Sangat Kurang Baik & $\leq 5.00$ & 3 & 1,16 \\
Kurang Baik & $5.01-10.00$ & 17 & 6,59 \\
Cukup Baik & $10.01-15.00$ & 121 & 46,90 \\
Baik & $15.01-20.00$ & 75 & 29,07 \\
Sangat Baik & $\geq 20.01$ & 42 & 16,28 \\
\hline & & 258 & 100,00 \\
\hline
\end{tabular}

Sumber: Diolah dari angket nomor: 11,1 2,1 3, 14, dan 15 .

Tabel 4 menyajikan gambaran kecerdasan siswa pada umumnya baik, hanya sebagian kecil yang kurang baik, tetapi hampir setengahnya masuk pada kategori cukup baik (46,90\%). Ini memberi arti bahwa siswa di SMA Negeri 5 Samarinda memiliki penalaran moralitas kecerdasan yang baik. Seseorang dimanapun, sekolah atau tidak sekolah perlu memiliki tingkat kecerdasan yang layak dalam hidupnya, karena hidup merupakan perjuangan berpikir. Pembelajaran berbasis karakter menumbuhkan perilaku untuk bersikap adil pada diri siswa. Keadilan sebagai bagian dari nilai sosial memiliki makna yang amat luas, bahkan pada suatu titik bisa bertentangan dengan hukum sebagai salah satu tata nilai sosial (Nasution, 2016:3).

Tabel 5. Gambaran Sikap Keadilan Siswa

\begin{tabular}{lcrr}
\hline \multicolumn{1}{c}{ Kategori } & $\begin{array}{c}\text { Skor Sikap } \\
\text { Keadilan }\end{array}$ & f & \% \\
\hline Sangat Kurang Baik & $\leq 5.00$ & 5 & 1,94 \\
Kurang Baik & $5.01-10.00$ & 21 & 8,14 \\
Cukup Baik & $10.01-15.00$ & 109 & 42,25 \\
Baik & $15.01-20.00$ & 67 & 25,96 \\
Sangat Baik & $\geq 20.01$ & 56 & 21,71 \\
\hline & & $\mathbf{2 5 8}$ & $\mathbf{1 0 0 , 0 0}$ \\
\hline
\end{tabular}

Sumber: Diolah dari angket nomor: 16, 17, 18, 19, dan 20.

Berdasarkan tabel 5 dapat dinyatakan bahwa terdapat 10,08\% siswa memiliki sikap keadilan yang tidak mendukung terbentuknya karakter atau moralitas yang baik. Meskipun demikian terdapat sekitar 89,92\% memiliki sikap keadilan yang sesuai moralitas yang diharapkan. Sikap adil sangat diperlukan dalam kehidupan, karena tanpa keadilan akan menimbulkan ketidakstabilan sosial di masyarakat yang merugikan semua pihak. Through developing awareness and appreciation of the value of each individual in a diverse society, religious and moral education engenders responsible attitudes to other people. This awareness and appreciation will assist in counteracting prejudice and intolerance as children and young people consider issues such as sectarianism and discrimination more broadly (Scottish Government, 2009).

Sikap tanggung jawab atau bertangung jawab merupakan karakter yang ditanamkan dalam pembelajaran berbasis karakter. Tanggung jawab adalah sikap dan perilaku seseorang untuk melaksanakan tugas dan kewajibannya yang seharusnya dia lakukan, terhadap diri sendiri, masyarakat, lingkungan (alam, sosial, dan budaya), Negara dan Tuhan Yang Maha Esa (Ardila, Nurhasanah, \& Salimi, 2017). Gambaran sikap tanggung jawab siswa disajikan pada tabel 6. 
54 Instructional Development Journal (IDJ), Vol. 2, No. 2, Desember 2019, Hal. $49-59$

Tabel 6. Gambaran Sikap Tanggung Jawab Siswa

\begin{tabular}{lcrr}
\hline \multicolumn{1}{c}{ Kategori } & $\begin{array}{c}\text { Skor Sikap } \\
\text { Tanggung Jawab }\end{array}$ & f & $\%$ \\
\hline Sangat Kurang Baik & $\leq 5.00$ & 2 & 0,78 \\
Kurang Baik & $5.01-10.00$ & 10 & 3,88 \\
Cukup Baik & $10.01-15.00$ & 113 & 43,79 \\
Baik & $15.01-20.00$ & 81 & 31,40 \\
Sangat Baik & $\geq 20.01$ & 52 & 20,15 \\
\hline \multicolumn{4}{c}{} \\
\hline \multicolumn{4}{c}{ Sumber: Diolah dari angket nomor: 21, 22, 23, 24, dan 25. }
\end{tabular}

Sikap tanggung jawab perlu dimiliki oleh setiap orang yang hidup bermasyarakat. Sikap tanggung jawab menyangkut hak dan kewajiban, hak yang dimiliki seseorang merupakan kewajiban orang lan. Sebaliknya, kewajiban seseorang adalah hak orang lain. Dengan demikian, setiap perbuatan di masyarakat memiliki konsekuensi tanggung jawab. Tabel 6 menyajikan bahwa sekitar 93,34\% siswa memiliki sikap tanggung jawab yang berkontribusi positif terhadap penalaran dan perilaku moralitas.

Tabel 7. Gambaran Sikap Kepedulian Siswa

\begin{tabular}{lcrr}
\hline \multicolumn{1}{c}{ Kategori } & $\begin{array}{c}\text { Skor Sikap } \\
\text { Kepedulian }\end{array}$ & f & \% \\
\hline Sangat Kurang Baik & $\leq 5.00$ & 8 & 3,10 \\
Kurang Baik & $5.01-10.00$ & 22 & 8,53 \\
Cukup Baik & $10.01-15.00$ & 104 & 40,31 \\
Baik & $15.01-20.00$ & 69 & 26,74 \\
Sangat Baik & $\geq 20.01$ & 55 & 21,32 \\
\hline \multicolumn{4}{c}{ Sumber: Diolah dari angket nomor: 26, 27, 28, 29, dan 30. }
\end{tabular}

Tabel 7 memperlihatkan aspek kepedudian siswa, meskipun terdapat 11,63\% siswa memiliki sikap kepedulian yang kurang mendukung pada aspek moraliltas secara keseluruhan, namun selebihnya yaitu 88,36\% masuk pada kategori yang positif untuk berkontribusi pada karakter yang berakhlak mulia. Kehidupan bermasyarakat memerlukan sikap saling peduli antara sesama anggotanya sehingga dapat tercipta kehidupan bermasyarakat yang harmonis saling menghormati.

Selain sikap peduli, yang tak kalah penting adalah sikap toleransi dalam masyarakat, yaitu untuk menghindari disharmoni akibat keragaman budaya, etnik, status sosial dan agama. Keragaman di masyarakat tidak bisa dihindari, sehinga sikap toleransi ini menjadi karakter yang dapat menjamin kehidupan yang dinamis dalam kedamaian. Jika seseorang bersikap intoleransi dapat menyebabkan ketegangan dan perselisihan yang berujung pada perpecahan di masyarakat.

Tabel 8. Gambaran Sikap Toleransi Siswa

\begin{tabular}{lcrr}
\hline \multicolumn{1}{c}{ Kategori } & $\begin{array}{c}\text { Skor Sikap } \\
\text { Toleransi }\end{array}$ & $\mathrm{f}$ & \multicolumn{1}{c}{$\%$} \\
\hline Sangat Kurang Baik & $\leq 5.00$ & 2 & 0,78 \\
Kurang Baik & $5.01-10.00$ & 9 & 3,48 \\
Cukup Baik & $10.01-15.00$ & 124 & 48,06 \\
Baik & $15.01-20.00$ & 76 & 29,46 \\
Sangat Baik & $\geq 20.01$ & 47 & 18,22 \\
\hline \multicolumn{4}{r}{} \\
\hline
\end{tabular}

Sumber: Diolah dari angket nomor: 31, 32, 33, 34, dan 35.

Pada umumnya penalaran moral siswa terhadap sikap toleransi sangat mendukung terbentuknya karakter moral. Sekitar 95,72\%, siswa bersikap toleran dengan berkaegori baik dalam pembentukan karakter.

Tabel 9. Gambaran Sikap Demokratis Siswa

\begin{tabular}{lcrr}
\hline \multicolumn{1}{c}{ Kategori } & Skor Sikap & f & \multicolumn{1}{c}{$\%$} \\
\hline Sangat Kurang Baik & Demokratis & 1 & 0,39 \\
Kurang Baik & 55.00 & 7 & 2,71 \\
Cukup Baik & $10.01-10.00$ & 95 & 36,82 \\
Baik & $15.01-20.00$ & 81 & 31,40 \\
Sangat Baik & $\geq 20.01$ & 74 & 28,68 \\
\hline & & 258 & 100,00 \\
\hline
\end{tabular}

Sumber: Diolah dari angket nomor: 36, 37, 38, 39, dan 40.

Kehidupan bermasyarakat perlu dukungan sikap demokratis warganya untuk mencapai suatu kehidupan yang dinamis berdasar pada kerukunan dan kebersamaan. Sikap demokratis menjadi bagian penting dalam bermasyarakat karena pada hakekatnya demokratis merupakan implementasi saling menghargai, tidak memaksakan kehendak atau bentuk-bentuk 
lainnya yang serupa. Sikap demokratis siswa yang disajikan dalam tabel 9 dapat dinyatakan positif berkontribusi terhadap pembentukan moralitas. Sekitar 96,90\%, sikap siswa mendukung kehidupan yang demokratis yang menjadi bagian karakter atau moral.

Tabel 10. Gambaran Sikap Cinta Tanah Air

\begin{tabular}{|c|c|c|c|}
\hline Kategori & $\begin{array}{c}\text { Skor Sikap } \\
\text { Cinta Tanah Air }\end{array}$ & f & $\%$ \\
\hline Sangat Kurang Baik & $\leq 5.00$ & 1 & 0,39 \\
\hline Kurang Baik & $5.01-10.00$ & 5 & 1,94 \\
\hline Cukup Baik & $10.01-15.00$ & 103 & 39,92 \\
\hline Baik & $15.01-20.00$ & 83 & 32,17 \\
\hline Sangat Baik & $\geq 20.01$ & 66 & 25,58 \\
\hline \multicolumn{2}{|c|}{ Jumlah } & 258 & 100,00 \\
\hline
\end{tabular}

Sumber: Diolah dari angket nomor: 41, 42, 43, 44, dan 45.

Untuk mewujudkan rasa kebangsaan yang tinggi, maka kecintaan terhadap tanah air perlu dipupuk pada masyarakat. Cinta terhadap tanah air akan menjadi perekat kokohnya Negara Kesatuan Republik Indonesia. Sikap cinta tanah air sekitar 97,67\% ditunjukkan berkontribusi pada moralitas atau karakter, seperti disajikan oleh tabel 10. Artinya siswa bersikap positif terhadap negerinya, yaitu Republik Indonesia. Hal ini sering menjadi pertanyaan banyak pihak terhadap loyalitas generasi muda dalam menopang kelangsungan bangsa dan negara. Sikap tangguh dalam menghadapi hambatan dan atau persoalan diperlukan oleh siswa sebagai generasi penerus bangsa. Keberlangsungan suatu bangsa terletak pada ketangguhan rakyatnya, tak terkecuali siswa sebaga remaja penerus bangsa. Tanpa memiliki karakter tangguh, remaja sebagai generasi penerus bangsa akan mudah dikuasai dalam waktu yang singkat. Dengan demikian, pembelajaran berbasis karakter merupakan pelestarian atau konsevasi nilai-nilai yang diturunkan oleh generasi pendahulu.

Tabel 11. Gambaran Sikap Tangguh Siswa

\begin{tabular}{|c|c|c|c|}
\hline Kategori & $\begin{array}{l}\text { Skor Sikap } \\
\text { Tangguh }\end{array}$ & $\mathrm{f}$ & $\%$ \\
\hline Sangat Kurang Baik & $\leq 5.00$ & 2 & 0,78 \\
\hline Kurang Baik & $5.01-10.00$ & 19 & 7,36 \\
\hline Cukup Baik & $10.01-15.00$ & 92 & 35,66 \\
\hline Baik & $15.01-20.00$ & 87 & 33,72 \\
\hline Sangat Baik & $\geq 20.01$ & 58 & 22,48 \\
\hline \multicolumn{2}{|c|}{ Jumlah } & 258 & 100,00 \\
\hline
\end{tabular}

Sumber: Diolah dari angket nomor: 46, 47, 48, 49, dan 50.

Berdasarkan tabel 11, nampak jelas bahwa kondisi sikap ketangguhan siswa sebanyak 91,86\% berkontribusi pada aspek moralitas bangsanya. Dengan demikian, sikap siswa memiliki dukungan yang positif terhadap terwujudnya ketangguhan diri dalam membangun karakter akhlak mulia. Ketangguhan tidak terbatas pada fisik, tetapi juga aspek moralitasnya. Mentalitas yang kuat dan tangguh menjadi awal bagi terbentuknya negara tangguh.

Tabel 12. Gambaran Sikap Santun Air Siswa

\begin{tabular}{lcrr}
\hline \multicolumn{1}{c}{ Kategori } & $\begin{array}{c}\text { Skor Sikap } \\
\text { Santun }\end{array}$ & f & \% \\
\hline Sangat Kurang Baik & $\leq 6.00$ & 1 & 0,39 \\
Kurang Baik & $6.01-12.00$ & 4 & 1,55 \\
Cukup Baik & $12.01-18.00$ & 78 & 30,23 \\
Baik & $18,01-20.00$ & 94 & 36.43 \\
Sangat Baik & $\geq 20.01$ & 81 & 31,40 \\
\hline \multicolumn{4}{c}{ Sumber: Diolah dari angket nomor: $51,52,33,54,55$, dan 56.} \\
\hline
\end{tabular}

Selanjutnya tabel 13 menyajikan gambaran penalaran moralitas dari seluruh aspek, yang merupakan total aspek. Berdasarkan data tabel 13 tersebut, tersaji secara jelas lebih dari setengahnya siswa memiliki penalaran moralitas yang baik (65,05\%), dan hanya sebagian kecil yang memiliki penalaran moralitas kurang baik (0,78\%). Dengan demikian, sekitar 99,22\% memiliki penalaran moralitas yang positif terhadap pembangunan karakter.

Tabel 13. Gambaran Penalaran Moralitas Siswa

\begin{tabular}{lcrr}
\hline \multicolumn{1}{c}{ Kategori } & $\begin{array}{c}\text { Skor Penalaran } \\
\text { Moralitas }\end{array}$ & f & $\%$ \\
\hline Sangat Kurang Baik & $\leq 56.00$ & 0 & 0,00 \\
Kurang Baik & $56.01-112.00$ & 2 & 0,78 \\
Cukup Baik & $112.01-168.00$ & 69 & 26,74 \\
Baik & $168,01-224.00$ & 169 & 65,50 \\
Sangat Baik & $\geq 224.01$ & 18 & 6,98 \\
\hline & & 258 & 100,00 \\
\hline
\end{tabular}


56 Instructional Development Journal (IDJ), Vol. 2, No. 2, Desember 2019, Hal. 49-59

Sumber: Diolah dari angket nomor: 51, 52, 33, 54, 55, dan 56.

Hidup bermasyarakat yang beradap diperlukan norma yang mengatur pola interaksi sosial sesama anggota masyarakat. Sikap santun menjadi prasyarat utama untuk terwujudnya interaksi sosial antara seseorang dengan orang lain. Berdasarkan tabel 12, hampir seluruh siswa memiliki sopan santun yang layak untuk keperluan komunikasi dalam interaksi sosial sekitar 98,06\%, dan hanya sebagian kecil yang memiliki sikap sebaliknya (1,94\%).

\section{PEMBAHASAN}

Uji validitas berdasarkan content untuk menghasilkan nilai koefisien item instrument terhadap totalnya dengan Pearson Product moment diperoleh $r_{\text {hitung }}$ paling rendah sebesar 0,721, dan tertinggi 0,895. Hal ini seluruh item instrument dinyatakan valid. Menurut Kaplan dan Saccuzzo (2005) yang dikutif (Widjaja \& Sandjaja, 2013:9) menyatakan sebuah tes yang memiliki koefisien reliabilitas berkisar antara 0,7 sampai 0,8 dinyatakan valid. Uji reliabilitas instrument untuk melihat koefisien Cronbach's Alpha sebesar 0,942, yang berarti instrument penelitian reliabel atau memiliki tingkat keajegan sangat tinggi. Selanjutnya uji normalitas dan linieritas memperlihatkan hasil bahwa nilai sig. Shapiro-Wilk untuk masing-masing variabel sebesar 0,065>0,05 dan 0,074>0,05, sedangkan sig. Devistion from linierity 0,062>0,05 maka dua variabel dalam kajian ini memiliki hubungan linier. Dengan demikian, analisis statistik dapat dilanjutkan.

\section{Uji hipotesis}

Pengujian terhadap hipotesis penelitian menggunakan pendekatan uji regresi linier dengan ketentuan sebagai berikut:

$\mathrm{H}_{0}$ diterima jika $\mathrm{F}_{\text {hitung }} \leq \mathrm{F}_{\text {tabel }}$ menolak $\mathrm{H}_{a}$

$\mathrm{H}_{\mathrm{a}}$ diterima jika $\mathrm{F}_{\text {hitung }}>\mathrm{F}_{\text {tabel }}$ menolak $\mathrm{H}_{0}$

Hipotesis penelitian tentang relevansi prestasi belajar dengan penalaran moralitas siswa sebagai berikut:

$\mathrm{H}_{0}$ :Prestasi belajar siswa tidak berpengaruh positif secara signifikan terhadap penalaran moralitas.

$\mathrm{H}_{\mathrm{a}}$ :Prestasi belajar siswa berpengaruh positif secara signifikan terhadap penalaran moralitas.

Berdasarkan analisis statistik regresi diketahui nilai $F_{\text {hitung }}=23,045$, sedangkan $F_{\text {tabel }} 3,87804$, yang berarti menerima $\mathrm{H}_{a}$ menolak $\mathrm{H}_{0}$. Dengan demikian, prestasi belajar siswa berpengaruh signifikan terhadap penalaran moralitasnya. Analisis koefisien korelasi independent variable (prestasi belajar) dengan dependent variable (penalaran moralitas) sebesar 0,683 (derajat hubungan kuat) dan determinasi sebesar 0,4665 memberi makna bahwa penalaran moralitas siswa sebesar 46,65\% ditentukan oleh faktor prestasi belajarnya, dan 53,35.\% ditentukan faktor lain. Faktor lain yang mungkin berpengaruh terhadap penalaran moralitas antara mata pelajaran lainnya, lingkungan, motivasi, atau status sosial ekonomi orang tua anak. Melalui pembelajaran berbasis karakter sangat memungkin nilai raport atau prestasi belajar dapat menjadi prediktor terhadap perilaku moral siswa. Dengan demikian, prestasi belajar tidak hanya menggambarkan kemampuan intelektual tetapi juga kemampuan moralitasnya. Mengingat penilaian merupakan kegiatan yang memiliki banyak fungsi, maka untuk membangun karakter siswa dapat dilakukan melalui peran guru sebagai penilai karakter. Setidaknya aspek kegiatan penilaian akan memberikan informasi yang bermanfaat kepada guru, orang tua, sekolah dan paling utama siswa (Heryanto, 2018).

\section{SIMPULAN DAN SARAN}

\section{Simpulan}

Pembelajaran berbasis karakter akan menjadi daya dukung yang sangat kuat untuk menghasilkan suatu penilaian yang mampu menggambar inteltual siswa sekaligus perilaku moralnya. Pengintegrasian aspek moral dalam materi pelajaran merupakan pembelajaran yang tepat dalam situasi global yang mengikis nilai moralistas. Pelaksanaan pembelajaran berbasis karakter tidak dapat berjalan sendirian tetapi diperlukan dukungan lain sehingga bisa optimal. Dukungan tidak hanya terbatas pada kurikulum, tetapi juga sumber daya manusia, fasilitas, waktu dan dana yang tersedia harus memadai. Pembelajaran berbasis karakter selama ini lebih menekankan pada fokus kegiatan belajar mengajar di kelas (intra-kurikuler), sedangkan kegiatan ekstra-kurikuler masih belum optimal. Penyediaan fasilitas ibadah hanya terbatas pada siswa muslim, sedangkan lainnya masih belum terperhatikan.

\section{Saran}

Pembelajaran berbasis karakter membutuhkan berbagai fasilitas untuk mendukungnya, mulai dari kurikulum, sumber daya manusia, dan dukungan dana. Oleh sebab itu, untuk mencapai proses pembelajaran yang optimal penyediaan fasilitas harus diupayakan selayak mungkin. Proses pembelajaran yang dilaksanakan di SMA Negeri 5 masih memerlukan fasilitas ibadah yang memadai, terutama untuk siswa yang bukan beragama Islam. Temuan tentang kontribusi prestasi belajar 
sosiologi terhadap penalaran moralitas sebesar 46,65\% maka 53,35\% di luar itu perlu dioptimalkan terutama seluruh mata pelajaran berintegrasi dengan nilai-nilai karakter akhlak mulia.

\section{DAFTAR RUJUKAN}

Ardila, R. M., Nurhasanah, N., \& Salimi, M. (2017). Pendidikan Karakter Tanggung Jawab dan Pembelajarannya di Sekolah. In Prosiding Seminar Nasional Inovasi Pendidikan (pp. 79-85). FKIP UNS.

Aziz, P. (2011). Analisis Konsep Kecerdasan Perspektif Howard Gardner (Multiple Intelligences) dan Penerpannya Dalam Pembelajaran Pendidikan Agama Islam. Skripsi, 1-176.

Buddyarti, G. (2003). Pengertian dan Ruang Lingkup Sosiologi. Retrieved from https://www.academia.edu/16974813/ Pengertian_dan_Ruang_Lingkup_Sosiologi

Dewi, D. A. N. N. (2018). Modul Uji Validitas dan Reliabilitas. Retrieved from www.researchgate.net/

Fathoni, A. (2015). Pembelajaran Berbasis Karakter. Prosiding Seminar Nasional dan Call For Papers, ISBN: 978-(2), 323-332.

Fathurrohman, M. (2016). Pengembangan Budaya Religius Dalam Meningkatkan Mutu Pendidikan. Ta'allum, 04(01), 1942.

Hadi, Y. (2014). Pendidikan Sebagai Wahana Pembentukan Karakter. Seminar Nasional dan Temu Alumni. Retrieved from http://pps.uny.ac.id/sites/pps.uny.ac.id/files/ Prosiding SEMNAS \%26 Temu Alumni 2014.pdf\#page=138

Herningsih, H., Fatmawati, F., \& Salim, I. (2015). Penyebab Terjadinya Perilaku Menyimpang 'Ngelem' Pada Siswa di SMPN 3 Subah Kabupaten Sambas. Jurnal Pendidikan dan Pembelajaran Untan, 1(1), 1-10.

Heryanto. (2018). Model Penilaian Hasil Belajar dan Karakter. Naturalistic, 2(2), 118-128.

Mak, W. S. (2014). Evaluation of a Moral and Character Education Group for Primary School Students. Discovery-SS Student EJournal, 3, 142-164. Retrieved from http://ssweb.cityu.edu.hk/download/RS/E-Journal/Vol3/journal5.pdf

Muhasin. (2017). Budaya Kejujuran Dalam Menghadapi Perubahan Zaman (Studi Fenomenologi Masyarakat Islam Modern) Muhasim. Palapa, 5(1), 174-195.

Murti, S., \& Heryanto. (2016). Pengaruh Kualitas Interaksi Sosial di Lingkungan Keluarga terhadap Prestasi Belajar Siswa. Al Ibtida, 3(2), 253-268.

Nasution, B. (2016). Kajian Filosofis tentang Hukum dan Keadilan Dari Pemikiran Klasik Sampai Modern. Al-Ihkam, 11(2), $247-274$.

Pertiwi, A. (2017). Pengaruh Prestasi Belajar Pendidikan Kewarganegaraan terhadap Moralitas Siswa SMP Negeri 2 Patuk Gunung Kidul. Skripsi, 32. Retrieved from https://eprints.uny.ac.id/

Qashmer, A. F. (2016). Character Education and Adolescents' Moral Identity Development (Actual and Ideal) in Education With an Emphasis in Educational Psychology. In Disertasi (p. 104).

Romeral, L. F., Fernández, J. S., \& Fraguela, J. A. G. (2018). Moral Reasoning in Adolescent Offenders: A Meta-Analytic Review. Psicothema, 30(3), 289-294. https://doi.org/ 10.7334/psicothema2017.378

Ruyters, D., \& Miedema, S. (2011). Moral Education and Development. Journal of Social Philosophy (Vol. 31). https://doi.org/10.1111/0047-2786.00071

Samanci, N. (2015). A Study on The Link Between Moral Judgment Competences and Critical Thinking Skills. International Journal of Environmental and Science Education, 10(2), 135-143. https://doi.org/10.12973/ijese.2015.236a

Sanwong, K. (2010). Moral Based Thinking Process Skills for Students' Morality and Ethics Development. International Journal of Arts and Sciences, 3(17), 287-297.

Scottish Government. (2009). Religious and Moral Education Principles and Practice. Retrieved from http://www.educationscotland.gov.uk/Images/rme_principles_practice_tcm4-540203.pdf

Siyaswati, S. (2016). Moral Values in American Folktales: 'the Fisherman and His Wife'. Paramasastra, 3(1). https://doi.org/10.26740/parama.v3i1.1522

Sniras, S., \& Malinauskas, R. (2005). Moral Skills of Schoolchildren. Social Behavior and Personality, 33(4), 383-390. https://doi.org/10.2224/sbp.2005.33.4.383

Stolley, K. (2005). The Basics of Sociology. Greenwood Press (Fisrt). London: Greenwood Press.

Sudrajat, A. (2011). Mengapa Pendidikan Karakter? Staff.Uny.Ac.id, 1(1), 47-58. https://doi.org/10.21831/jpk.v1i1.1316 
58 Instructional Development Journal (IDJ), Vol. 2, No. 2, Desember 2019, Hal. 49-59

Sutrisno, A. (2015). Sebelas Nilai Karakter Konservasi Unnes. Retrieved from http://blog.unnes.ac.id/akhmadsutrisno/ 2015/11/14/sebelas-nilai-karakter-konservasi

Vessels, G., \& Huitt, W. (2011). Moral and Character Development. Educational Psychology Interactive, 1-31. Retrieved from http://www.edpsycinteractive.org/topics/morchr/ morchr.html

Volokh, E. (2007). Moral Development Through Play During Early Childhood. The Aluminum Association, Inc. https://doi.org/10.1002/ejoc.201200111

Widjaja, F., \& Sandjaja, S. (2013). Uji validitas dan Reliabillitas Index of Teaching Stress (ITS). Jurnal NOETIC Psychology, $3(2), 104-127$.

Wuryati. (2012). Fenomena Perilaku Menyimpang Remaja di Kecamatan Rowosari Kabupaten Kendal. Journal of Educational Social Studies, 1(2), 72-77. https://doi.org/10.15294/jess.v1i2.733 